\title{
FATIGUE FAILURE CRITERION FOR HYDRAULIC GRADED IRON AND STEEL SLAG BASE-COURSE AND ITS IMPLEMENTATION INTO THE J APANE SE ASPHALT PAVEMENT DESIGN METHOD
}

\author{
Nobuyuki Y OSHIDA ${ }^{1}$ \\ ${ }^{1} \mathrm{M}$ ember of J SCE, A ssociate Professor, R esearch Center for U rban Safety and Security, K obe University \\ (1-1, Rokkodai, N ada-ku, K obe 657-8501, Japan) \\ E-mail: nyoshida@kobe-u.ac.jp
}

\begin{abstract}
This paper first illustrates briefly the possibility of fatigue failure of hydraulic, graded iron and steel slag base-course based on a follow-up on-site investigation on a trial asphalt pavement. Then, its fatigue failure criterion is derived based on repeated bending fatigue tests on the beam specimens prepared in the experimental yard. This failure criterion is implemented into the design flow of the J apanese mechanistic-empirical structural design method of asphalt pavement and an example analysis is presented. It is shown that the thickness of the base-course required for the designated design life can be reduced roughly by half with this modification of the current design flow.
\end{abstract}

Key Words: iron and steel slag, base-course, fatigue failure, asphalt pavement, structural design

\section{INTRODUCTION}

In Japan, the hydraulic graded iron and steel slag base-course material (hereafter HM S) first appeared in the 1978 edition of the A sphalt Pavement M anual published by the Japan Road A ssociation ${ }^{1)}$. A round the same time, the material was included as one of the base-course materials in the Japanese industrial standards ${ }^{2)}$. Since the material literally possesses a hydraulic nature, it should be more popular in road constructions: it can be a strengthened base-course after construction.

A Japanese mechanistic-empirical design method of pavement structures was first introduced in the 1992 edition of the A sphalt Pavement $M$ anual as an alternative design method using the multilayer elastic theory ${ }^{3)}$. Since then, it had been revised twice as a theoretical design method in the Pavement Design Construction Guide and the latest edition was issued in 2006 ${ }^{4}$. The Pavement Design $M$ anual published at the same time includes some design examples for users ${ }^{5)}$. The mechanistic-empirical design method aims to use pavement material effectively and adopt new pavement structures but has not been used so much. There seems to be much room for improvement.
A ny bound layer has a possibility of fatigue failure under repeated loads but the J apanese structural design method does not take this into account. The possibility of fatigue failure needs to be considered, though detailed investigation has not been carried out on whether or not the base-course has experienced fatigue failure in reality. The failure of HM S base-course earlier than the surface- and binder-course of asphalt mixtures should be avoided.

Little attention has been paid to the development of a fatigue failure criterion for not only the HMS base-course but also for other bound base-course. A mong the few available studies, $\mathrm{N}$ ishi et al. ${ }^{6)}$ derived a relationship of tensile strain at the bottom of the HM S layer with the number of load applications based on a series of accelerated loading tests on a circular experimental road. On the other hand, fatigue failure criteria for chemically bound material such as cement-treated ones can be found in the literature. Some are expressed in terms of tensile strain at the bottom of the layer and the number of load applications ${ }^{\text {e.g. }}$, 7,8) and some are in terms of the stress ratio of applied bending stress to static bending strength and the number of load applications $s^{\mathrm{e} .9,9), 10 \text { ). }}$.

In the following sections, the possibility of fa- 
tigue failure of HMS base-course is first briefly illustrated based on a follow-up on-site investigation on a trial asphalt pavement. Then, its fatigue failure criterion is derived based on repeated bending fatigue tests on the beam specimens. Finally, an attempt is made to implement this failure criterion into the flowchart of the Japanese mechanistic-empirical structural design of asphalt pavement and an example analysis is presented.

\section{DEVELOPMENT OF HORIZONTAL STRAIN ON TRIAL PAVEMENT}

\section{(1) O utline of instrumented trial pavement}

A $n$ instrumented asphalt pavement section was located at the $\mathrm{N}$ akashima-A nase line of $\mathrm{H}$ yogo prefecture road in Himeji City during the expansion work on an existing paved road. It was a four-lane road (two lanes per direction) and designed for a one-way daily traffic volume of heavy vehicles ranging from 1,001 to 3,000 cars with a design vehicle speed of $60 \mathrm{~km} / \mathrm{h}$.

The pavement consisted of a $50 \mathrm{~mm}$ thick dense-graded asphalt surface-course, a $50 \mathrm{~mm}$ thick coarse-graded asphalt mid-course, a $50 \mathrm{~mm}$ thick coarse-graded asphalt binder-course, a $100 \mathrm{~mm}$ thick HM S base-course, a $100 \mathrm{~mm}$ thick crusher-run subbase-course and on-site subgrade, as shown in Fig. $\mathbf{1}^{11)}$. The materials used in the surface-, mid-, binder- and subbase-course were recycled ones, the HMS in base-course consisted mainly of air-cooled

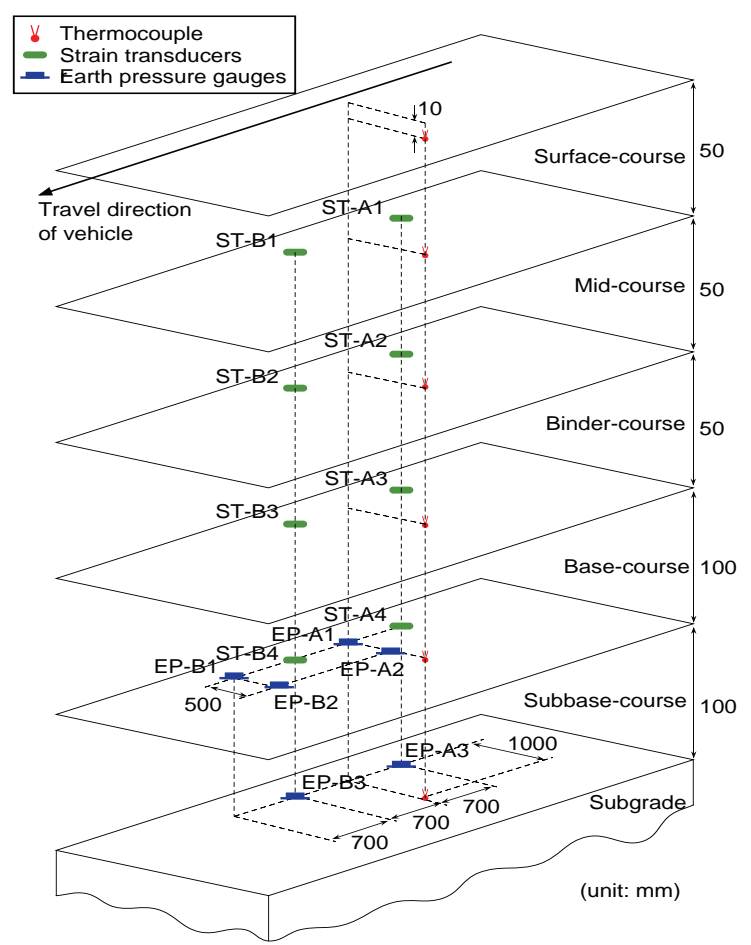

Fig.1 Instrumented trial asphalt pavement section. blast-furnace slag, and the subgrade was a blackish soil $100 \mathrm{~mm}$ thick underlain by a yellow-whitish in-situ soil. E mbedded-type strain transducers, earth pressure gauges and thermocouples were installed at the pre-specified locations in the near-centerline lane bound for Nakashima, as indicated in Fig.1. All the strain transducers were placed parallel to the travel direction of vehicles.

The instrumented asphalt pavement was completed on July 30, 2004 and opened for traffic on M arch 16, 2005.

\section{(2) Vetical distribution of horizontal strain pro- duced by the passage of loaded vehicles}

A n on-site investigation was carried out by employing a dump truck and occasionally a FWD vehicle. The wheel arrangement of the dump truck consisted of a front single axle with single tire and tandem rear axles with dual tires. The total weight was adjusted to $196 \mathrm{kN}$ : the front axle weighed 96 $\mathrm{kN}$ and the tandem rear axles $100 \mathrm{kN}$. The dump truck ran such that the center of the rear dual tires passed on the alignment of embedded instruments (hereafter called center-passing). Three targeted speeds of vehicle were considered 5,15 and 30 $\mathrm{km} / \mathrm{h}$. For more details, please refer to $Y$ oshida et al. ${ }^{11), 12)}$.

Figure 2 shows the vertical distribution of peak horizontal strains recorded when the front dual wheels of the tandem rear axles have passed just above the embedded strain transducers in summer time. The vehicle speed was $15 \mathrm{~km} / \mathrm{h}$ and positive values mean tensile strains. Here, it has to be said that, during each on-site investigation, the average temperatures of the asphalt layers in summer were $42.5^{\circ} \mathrm{C}$ in $2005,35.2^{\circ} \mathrm{C}$ in $2006,42.6^{\circ} \mathrm{C}$ in 2007 and $52.4^{\circ} \mathrm{C}$ in 2008 ; on the other hand, the temperatures in winter ranged from $6.5^{\circ} \mathrm{C}$ to $8.4^{\circ} \mathrm{C}$. It is seen that in 2005 , a tensile strain of about $150 \mu$ occurred at the bottom of the binder-course, which was the largest, and that a relatively large tensile strain, about $120 \mu$, took place at the bottom of the HMS

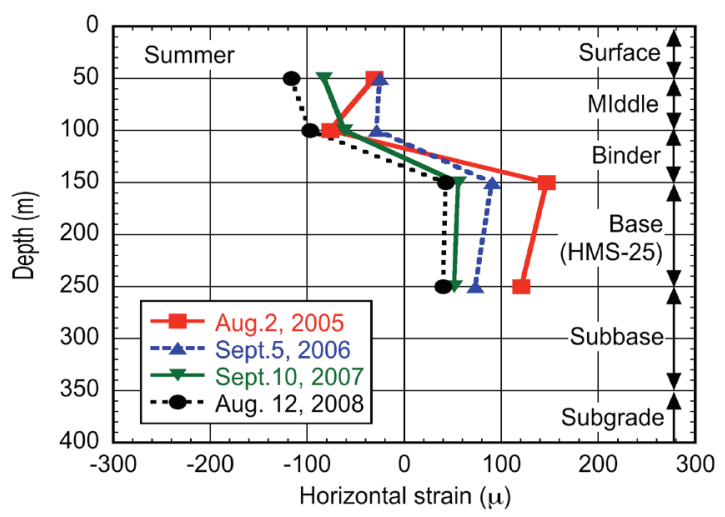

Fig.2 V ertical distribution of peak horizontal strains in summer. 
base-course. As time went by, tensile strains at the both locations became smaller and in 2007, the difference in the magnitude of tensile strain between the two locations became negligible: $58 \mu$ at the bottom of the binder-course and $50 \mu$ at that of the base-course.

It is also interesting to see in Fig. $\mathbf{2}$ that tensile strains at the bottoms of the binder-course and H M S base-course exhibited little difference between 2007 and 2008. A s stated earlier, the average temperature of the asphalt layers in 2008 was about $10^{\circ} \mathrm{C}$ higher than in 2007. Thus, this can be due to the development of hydraulicity inherent in the HMS base-course material.

On the other hand, the strain distributions in winter, though not shown here, were almost identical between the measuring years, and the magnitude of tensile strains at the bottoms of the binder-course and HM S base-course was almost the same ranging from $20 \mu$ to $40 \mu$.

Thus, it can be said that, just like the binder-course, the HM S base-course has a possibility of fatigue failure under repeated traffic loads. Also, damage to both the base-course and the binder-course appears much larger in summer than in winter just as to the binder-course.

\section{FATIGUE FAILURE CRITERION}

\section{(1) Hydraulic graded iron and steel slag tested and specimen preparation}

The hydraulic, graded iron and steel slag (HMS) tested in this study is commercially available in Japan and satisfies the quality requirements designated in the J apanese Industrial Standard ${ }^{2}$. It was a mixture of steel-making slag, air-cooled blast-furnace slag and some additives with undisclosed proportion. The maximum grain size was 25 $\mathrm{mm}$. The maximum dry density and optimum water content were $1.908 \mathrm{~g} / \mathrm{cm}^{3}$ and $15.7 \%$, respectively.

Specimens were made in the following manner. A part of the experimental yard in the research center was excavated down to about $500 \mathrm{~mm}$ from the ground surface and the excavated face was leveled. Then, a series of steel molds were placed: the inner size of each mold was $100 \mathrm{~mm}$ high, $100 \mathrm{~mm}$ wide and $400 \mathrm{~mm}$ long. A fter adjusting the water content to the optimum level, the HM S material was spread over the steel molds in one or two lifts and compacted to reach more than $95 \%$ of the maximum dry density using a road roller. A fter splaying asphalt on the compacted surface, the specimens with molds were cured in situ for the pre-specified periods of time.
When the time was right, the required number of the specimens with molds was dug out: each specimen was detached from the mold and served to the repeated bending fatigue tests after its top face had been trimmed.

\section{(2) Repeated bending fatigue test}

Repeated bending fatigue test were carried out using a four-point loading system as shown in Fig. ${ }^{13)}$. The repeated vertical load was applied in a sine wave with $5 \mathrm{~Hz}$ : the peak value was determined referring to the static bending strength but a base value of $40 \mathrm{~N}$ was imposed due to the restriction of apparatus. Each test continued until the number of load applications reached 13 million or until the specimen failed.

The deflection of specimen was measured using three eddy-current noncontact displacement sensors with targets glued on the lateral face of specimen (Fig.3).

The specimens cured for 90 and 270 days were tested. For each curing time, prior to the fatigue test, a static bending test was carried out on three specimens. The average static bending strengths were $0.962 \mathrm{MPa}$ for 90 -day cured specimens and 1.279 MPa for 270-day cured ones as shown in Fig.4, in which an extrapolation curve is also drawn. Considering the tendency of the uniaxial compres-

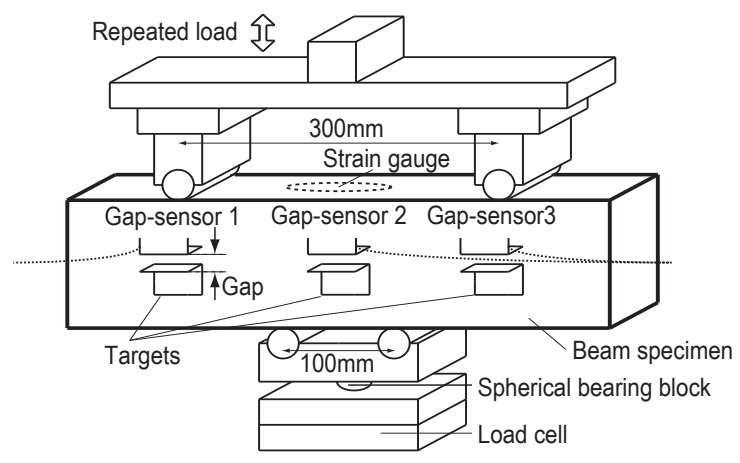

Fig.3 Repeated bending fatigue test setup.

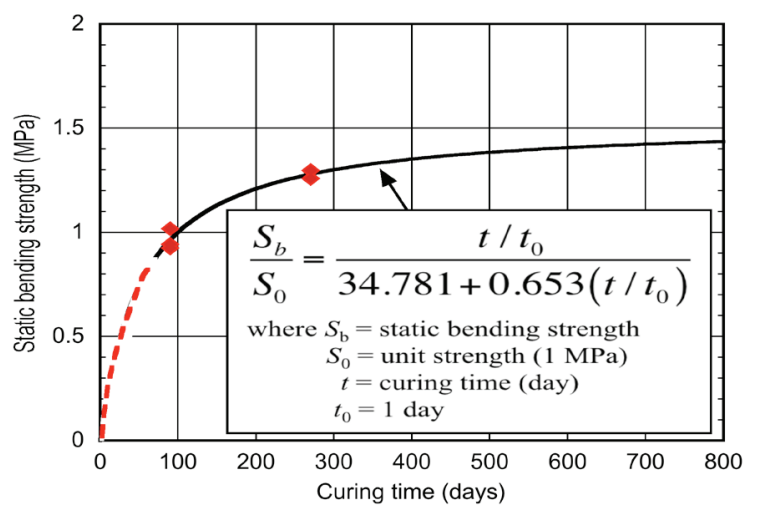

Fig.4 Relationship between static bending strength and curing time. 
sive strength of the HMS to increase with curing time ${ }^{14)}$, although not shown here, this extrapolation seems to be not unrealistic. Referring to these static bending strengths, the magnitude of applied load was selected for the repeated bending fatigue test as stated in the following section.

\section{(3) T est results and discussion}

Tested were twelve 90-day cured specimens and seven 270-day cured ones. Figure 5 shows the relationships between applied bending stress and the number of load applications to failure. In the figure, regression lines are also shown. It is noticed that the number of data points is smaller than the tested: this is because some specimens broke down during the load adjustment prior to test or some were excluded due to obvious abnormality. From the figure, it seems that there is not much difference in the relationship between the specimens cured for 90 and 270 days but that the slope of regression line seems to be smaller in 270-day cured ones.

As stated in the previous section, the static bending strength of 270-day cured specimens is about 1.3 times that of 90-day cured ones. Figure 6 shows the relationships of stress ratio (SR), which is the a ratio of applied bending stress $\left(\sigma_{b}\right)$ to static

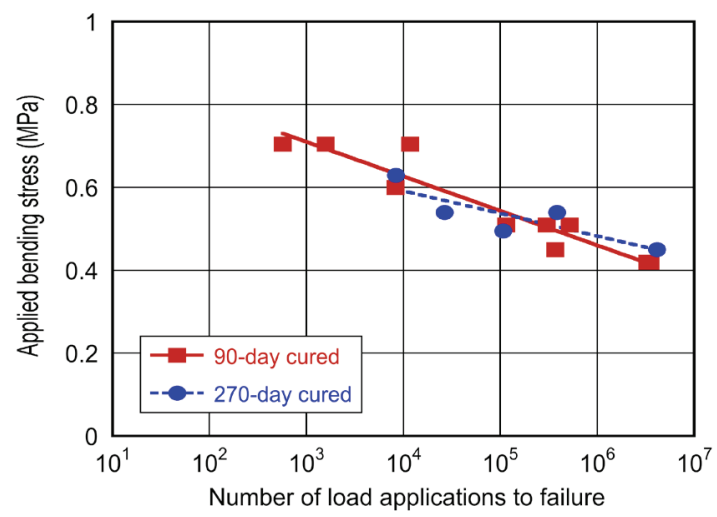

Fig.5 Relationship between applied bending stress and number of load applications to failure.

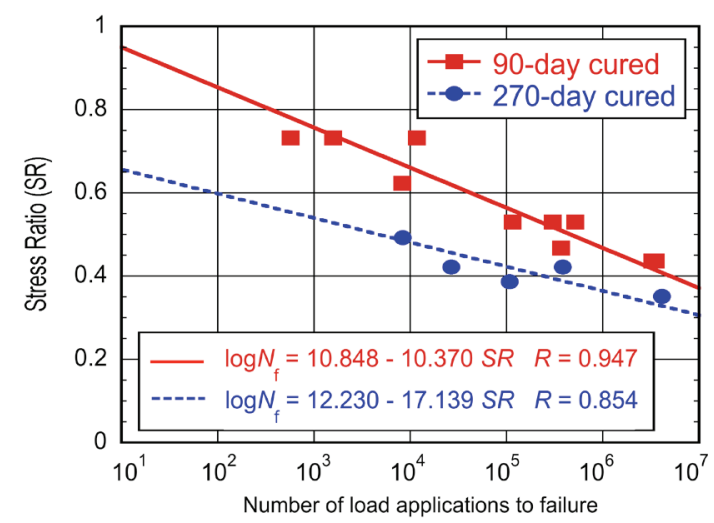

Fig.6 Relationships between stress ratio and number of load applications to failure. bending strength $\left(S_{b}\right)$, with the number of load applications to failure. The regression line for the 270-day cured specimens lies below that for the 90-day cured ones. This is because, while the static bending strength increases with curing time, the relationships of applied bending stress with the number of load applications to failure are almost the same between the two cured specimens. So, even if bending stress induced by the traffic load is constant or changes little with time, the stress ratio decreases with time due to increase of static bending strength.

The $y$-intercepts and slopes of the regression lines in Fig. $\mathbf{6}$ are plotted in $\mathbf{F i g . 7}$ together with their regression curves. Assuming that the regression equations in Fig. $\mathbf{6}$ hold, by applying the $y$-intercept and slope to the $\alpha$ and $\beta$ in Eq.1, respectively and arranging it, one can derive a fatigue failure equation specific to this HMS base-course material, Eq.2.

$$
\begin{gathered}
S R=\alpha-\beta \log \left(N_{f}\right) \\
\log N_{f}=7.185 e^{-0.00177 \cdot T}+3.661 e^{-0.00279 \cdot T} \\
-8.065 e^{-0.00279 \cdot T} \cdot S R
\end{gathered}
$$

where $N_{f}$ is the number of load applications to failure, $T$ is the curing time (days) and $S R$ is the stress ratio of applied bending stress ( $\sigma_{b}$ in $\mathrm{MPa}$ ) to static bending strength $\left(S_{b}\right.$ in $\left.\mathrm{MPa}\right)$. N ote here that this fatigue failure equation must be used together with the static bending strength which is the hyperbolic function of curing time as given in Fig.4.

\section{IMPLEMENTATION OF FATIGUE FAILURE CRITERION INTO THE CURRENT DESIGN METHOD}

\section{(1) C urrent design flowchart and its modification}

As mentioned in the INTRODUCTION, a mech-

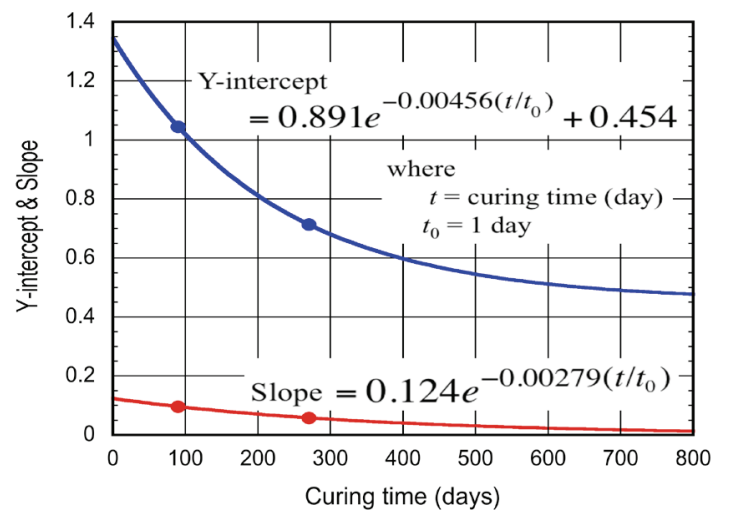

Fig.7 Relationships of $y$-intercept and slope of regression lines in Fig. $\mathbf{6}$ with curing time. 
anistic-empirical pavement design method was introduced in Japan in 1992 and was revised in 2006. Figure 8 shows the main part of its flow chart ${ }^{4}$. In the flow chart, the mechanistic evaluation is to judge whether or not: (i) asphalt mixture layers may fail by fatigue using the horizontal strain generated at its bottom face and the fatigue failure criterion and (ii) excessive vertical displacement takes place at the top face of subgrade using the vertical compressive strain generated at the location and the failure criterion for subgrade. Both failure criteria are those modified from the Al equation to meet Japanese circumstances. These judgments are made in terms of the accumulated number of wheels converted to $49 \mathrm{kN}$ by comparing the computed one with the required one.

The mechanistic evaluation block in the flowchart

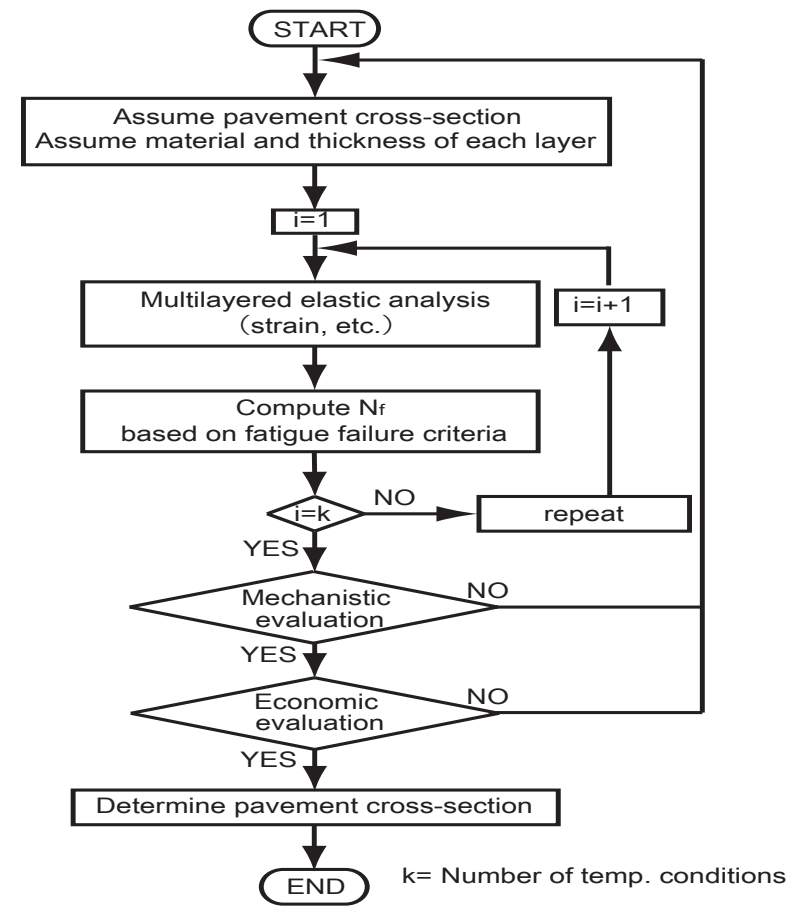

Fig.8 M ain part of flowchart of J apanese mechanistic-empirical pavement design method.

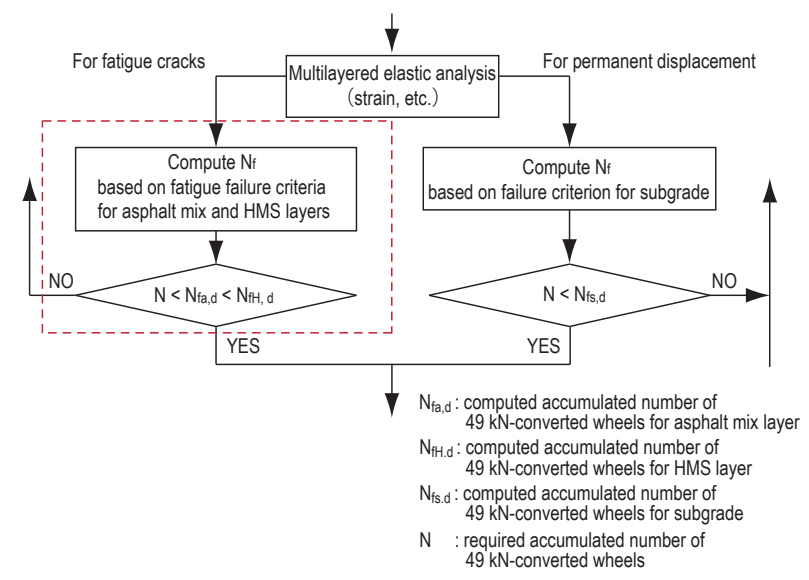

Fig.9 Mechanistic evaluation block and modified part enclosed with dashed line. is modified here for a possible evaluation of HMS base-course. As shown in Fig.9, possible fatigue failure in both the asphalt mixture and the HMS layers is judged and the calculation is repeated so that the accumulated number of $49 \mathrm{kN}$-converted wheels for HM S base-course becomes greater than that for the asphalt mixture layer, based on the idea that any base-course should not fail earlier than the asphalt mixture layers. The fatigue failure equation, $\mathrm{Eq} .2$, is used to calculate the accumulated number of $49 \mathrm{kN}$-converted wheels for the HM S layer.

\section{(2) Example analysis}

A three-layered asphalt pavement (an asphalt mixture layer, a HM S base-course and a sandy subgrade) is analyzed as an example here. A $n$ initial cross-section is determined following the $T_{A}$ design method described in the Pavement Design $\mathrm{M}$ anual ${ }^{6)}$, which is the empirical but most popular design method in Japan even today. The design conditions are assumed as follows: the design CBR of subgrade is $3 \%$ and the traffic condition is $N_{7}$, more than 3,000 vehicles per day per direction. The reliability degree is $90 \%$. From these, the $T_{A}$ method gives thicknesses of $200 \mathrm{~mm}$ and $450 \mathrm{~mm}$ for the asphalt mix layer and H M S base-course, respectively.

$\mathrm{N}$ ow, let us move on to the mechanistic-empirical design. Table 1 summarizes the input data required for a multilayered elastic analysis which was performed using the KENLAYER program ${ }^{15)}$. In the table, the Young's modulus values for HMS were determined referring to the results of the resilient modulus tests conducted on the long-term cured HMS specimens ${ }^{\text {e.g.,16). }}$. Regarding the Poisson's ratio, referring to the same experimental results and assuming that it is constant regardless of curing time, 0.20 was adopted. The loading condition is assumed precisely the same as exemplified in the Japanese pavement design manual| ${ }^{5)}$ as shown in Fig.10: dual wheels are assumed, each of which applies a uniformly distributed load of $0.61 \mathrm{M} \mathrm{Pa}$ on to the pavement surface at a $94 \mathrm{~mm}$ interval. The analysis started with the cross-section designed with the $T_{A}$ design method and was repeated decreasing the thickness of HM S base-course only.

It should be mentioned here that, in the analysis,

Table 1 Input data for multi-layered elastic analysis for example analysis.

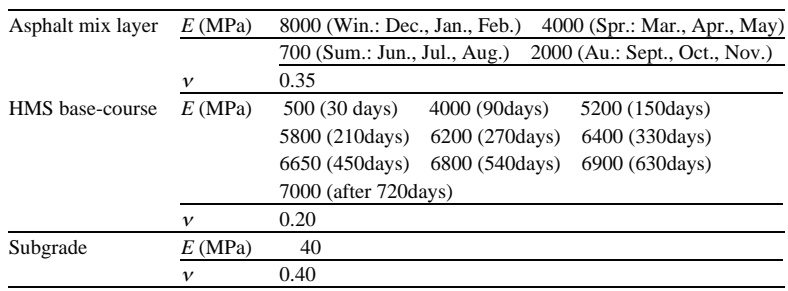


to detect the critical point, where the maximum tensile horizontal strain is generated, strains at the 10 locations on the bottom face of asphalt mixture layer are monitored: the center of dual tires, the center and outer edge of one tire, and seven locations between the center of dual tires and the center of one tire. Similarly, the tensile horizontal stresses generated at the 10 locations on the bottom face of $\mathrm{HM} \mathrm{S}$ base-course are al so monitored.

Here, to make it easier to imagine them, the calculation results are presented in terms of fatigue life in years instead of accumulated number of $49 \mathrm{kN}$-converted wheels, assuming that there is no increase in traffic volume with time. Figure $\mathbf{1 1}$ shows the relationships of the HMS thickness with the fatigue life of asphalt pavement. For the starting cross-section with the $150 \mathrm{~mm}$ thick asphalt mix layer and $450 \mathrm{~mm}$ thick HM S base-course, an unrealistically long life resulted. The fatigue life of HMS base-course decreases with its decreasing thickness. On the other hand, the fatigue life of asphalt mix layer increases as the base-course thickness decreases. This is probably due to the fact that the horizontal strain at the bottom of the asphalt mix layer under the center of dual wheels was not al ways tensile and also varies with a combination of elastic moduli of the asphalt mix layer and HMS base-course.

It is seen from Fig.11 that the thickness of HM S base-course of $233 \mathrm{~mm}$ gives fatigue lives of 70.6 years for the base-course and 56.5 years for the asphalt mix layer, which is considered to be optimum. Compared with the initial cross-section, the thickness of base-course is decreased by $217 \mathrm{~mm}$. Other cases, although not shown here, also gave decreased thickness for H M S base-course compared with those determined with the $T_{A}$ design method.

\section{CONCLUSIONS}

In this paper, a fatigue failure criterion for hydraulic graded iron and steel slag base-course was derived based on repeated bending fatigue tests on the beam specimens. It was a function of curing time and the stress ratio of applied bending stress to time-dependent static bending strength. This failure criterion was implemented into the flowchart of the Japanese mechanistic-empirical structural design method of asphalt pavement. An example analysis illustrated that: using this modified design flowchart, the thickness of HMS base-course layer could be reduced to roughly half of that designed with the traditional empirical design method. Despite the limited number of example analyses, it appears to capture the essence of the idea.

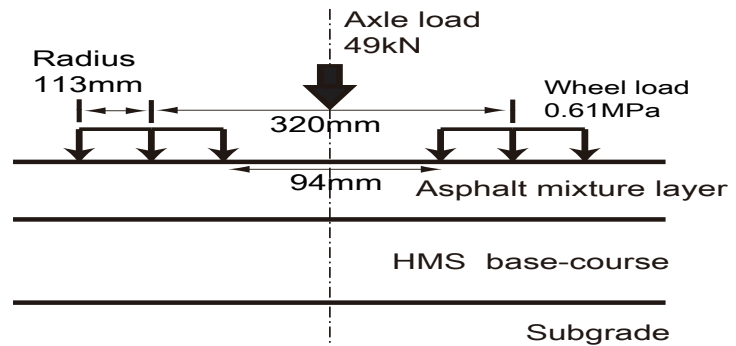

Fig.10 Loading condition for example analysis with three-layered asphalt pavement.

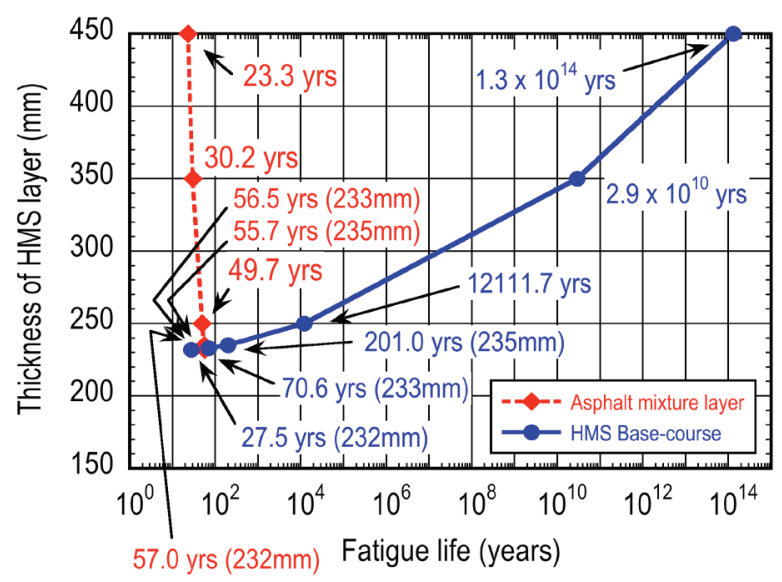

Fig.11 Relationships of HMS thickness with fatigue life of asphalt pavement.

\section{REFERENCES}

1) Japan Road A ssociation: A sphalt Pavement M anual, 1978. (in J apanese)

2) Japanese Standards Association: Iron and steel slag for road construction, JIS A 5015, 20pp., 1992.

3) J apan Road A ssociation: A sphalt Pavement M anual, 1992. (in J apanese)

4) Japan Road Association: Pavement Design and Construction Guide, 2006. (in Japanese)

5) Japan Road Association: Pavement Design M anual, 2006. (in J apanese)

6) Nishi, M., Tohyama, S., Ohashi, K. and Tunefuji, H.: Development of asphalt pavement performance curves based on circular road tests results, Research Report No. 37, Construction Engineering Research Institute Foundation, pp. 45-64, 1995.

7) Pretorius, P. C. and M onismith, C. L.: Fatigue Crack Formation and Propagation in Pavements Containing Soil-Cement Bases, Highway Research Record, No. 407, Washington, D.C., 1972.

8) Wang, M. C. and K ilareski, W. P.: Field Performance of Aggregate-Lime-Pozzolan Base Material, Transportation Research Record, N o. 725, TRB, 1979.

9) Symons, I. F .: A preliminary investigation to determine the resistance of cement-stabilized materials to repeated loading, TRRL Report LR 61, TRRL, 1967.

10) NCHRP: Guide for M echanistic-Empirical Design of new and rehabilitated pavement structures. Project 1-37A Final Report, Part 3. Design A nalysis. W ashington, D.C., 2004.

11) Y oshida, N., Okamoto, A., Funakoshi, T., Ioku, T., M ori, E., A rai, T., U wami, H. and Chiyohara, N .: In-situ dynamic response of asphalt pavement containing a hydraulic, graded iron and steel slag base-course, Proceedings, 10th International Conference on Asphalt Pavements, Quebec, Canada, ISA P code 10124, 2006. 
12) Y oshida, N., Furutani, T., M ori, E., Ioku, T. and Hirotsu, E.: Five years' follow-up of trial asphalt pavement: a better performance by iron $\&$ steel slag base-course, 17th World $M$ eeting and Exhibition, International Road Federation, Riyadh, Saudi A rabia, 2013. (submitted)

13) Furutani, T., Tanaka, T. and Y oshida, N.: Structural design of asphalt pavement considering fatigue failure of hydraulic, graded iron and steel slag base-course, Proceedings, 66th Annual Conference of J apanese Society of Civil Engineer, V-382, 2011. (in J apanese)

14) Y oshida, N., Sugita, T., M iyahara, T. and Hirotsu, E.: Influence of hydraulicity on resilient modulus and Poisson's ratio of hydraulic, graded iron and steel slag base-course material, Proceedings, 1st International Conference on Transportation Geotechnics, Nottingham, UK, pp.765-770, 2008.

15) Huang, Y . H.: KENLAYER Computer Program, Pavement Analysis and Design, 2nd Edition, Pearson Prentice Hall, pp. 94-146, 2004.

16) Kimura, $\mathrm{H}$.: Resilient Characteristics of HM S B ase-course $M$ aterial Cured for A L ong Period of Time. M.Sc. Thesis, Graduate School of Engineering, Kobe University, Kobe, Japan, 90p., 2010.

(Received J une 27, 2013) 